\title{
Metal Nanoparticle Modified Polysulfone Membranes for Use in Wastewater Treatment: A Critical Review
}

\author{
Heidi Lynn Richards, Priscilla G. L. Baker* , Emmanuel Iwuoha
}

Sensor Lab, Department of Chemistry, University of the Western Cape, Bellville, South Africa.

Email: ${ }^{*}$ pbaker@uwc.ac.za

Received May $4^{\text {th }}, 2012$; revised June $4^{\text {th }}, 2012$; accepted June $11^{\text {th }}, 2012$

\begin{abstract}
Membrane separation processes have been widely applied in the treatment of wastewater. Polysulphone (PSF) membranes are the most common membranes used in ultrafiltration of wastewater due to its mechanical robustness and structural and chemical stability. Unfortunately these membranes are mostly hydrophobic by nature and therefore highly susceptible to fouling. Many studies have been conducted to increase the hydrophilic properties of the polysulphone/ polyethersulfone membrane surface, more recently metal nanoparticles have been added to the polymer matrix in order to reduce fouling potential and increase membrane performance. $\mathrm{TiO}_{2}$ nanoparticles have proven successful in mitigating fouling of organic matter onto PES. Embedded Ag nanoparticles have improved virus removal from wastewater due to the bactericidal properties of silver. $\mathrm{Al}_{2} \mathrm{O}_{3}$ and most recently $\mathrm{ZrO}_{2}$ nanoparticles reduced the fouling rate of polyethersulfone membranes in wastewater, while the latter also showed lower flux decline of the composite membrane. These metal nanoparticles all impart specific properties onto the membrane surface. Scanning electron microscopy, steady state fouling rate and contact angle measurements are membrane characterisation techniques discussed in this review that reveal specific changes to membrane properties brought about by metal nanoparticles. This paper reviews the most recent developments and shortcomings of metal nanocomposite polysulfone and polyethersulfone (PES) membranes and strives to identify specific focus areas to consider in future research.
\end{abstract}

Keywords: Polysulfone (PSF); Polyethersulfone (PES); Metal Nanoparticles; Scanning Electron Microscopy; Contact Angle; Nanocomposite; Hydrophobicity

\section{Introduction}

The demand for new water resources has become increasingly urgent worldwide, due to a fast growing global population and increasing water demand. The re-use of treated wastewater effluent has become a reality and many industries use this water in their production processes.

Membrane bioreactor (MBR) technology is widely used for wastewater purification, but still suffers from major disadvantages, including irreversible membrane fouling and subsequent plant down-time. Membrane fouling is still regarded as the major drawback of the MBR process and without improved anti-fouling membranes this highly efficient technology will remain handicapped [1-6].

Polysulphone (PSF) membranes are the most common membranes used in ultrafiltration of wastewater due to its mechanical robustness and structural and chemical stability. Unfortunately PSF is a hydrophobic material, making its surface prone to fouling due to adsorptive mechanisms.

\footnotetext{
${ }^{*}$ Corresponding author.
}

Fouling can either be caused by cake formation on the surface of the membrane, or by adsorption of the foulants both on the surface and in the membrane pores $[7,8]$. Lee et al. [9] did filtration resistance studies that indicated the formation of the cake layer is the main cause leading to membrane fouling. Cake fouling occurs when foulants that are larger than the membrane pores, such as sludge flocs and colloids, form a cake layer on the membrane surface. Cake fouling is generally reversible and can be removed by backwashing or water flushing. Foulants that are comparable in size with the membrane pores, will cause adsorption on the pore walls and pore blocking. Foulant adsorption however is irreversible and can only be remedied by very harsh chemical cleaning [10].

Another drawback limiting the use of membrane technologies in wastewater treatment is the accumulation of microorganisms on the membrane surface and the subsequent adhesion of different types of organic and inorganic foulants. The membrane surface provides a selective, porous substrate which allows the transfer of certain molecules and the exclusion of some other molecules 
based on size. Biofouling occurs when live biofilm-forming bacteria and organics adhere to the membrane surface and multiplies, leading to clogging of the membrane pores and impaired function of the filtration system [11]. This biofilm formation has been shown to cause a greater flux decline than dead cells, with the major contributing factor to the increased hydraulic resistance of the membrane being the extracellular polymeric substances (EPS) surrounding the bacterial cells [12]. The predominant bacterial groups involved in the fouling of membranes, have been found to be Proteobacteria and Bacteroidetes.

\section{Metal Nanoparticle Modified Membranes}

Many studies have been conducted to increase the hydrophilic properties of the polysulphone membrane surface. These studies can be divided into three categories i.e. blending PSF with hydrophilic nanoparticles such as $\mathrm{SiO}_{2}, \mathrm{ZrO}_{2}$ and $\mathrm{TiO}_{2}$, grafting with hydrophilic polymers, monomers or functional groups and coating with hydrophilic polymers [13]. Blending with nanoparticles has attracted much interest in the past 10 years due to their convenient operation and mild conditions. Blending offers the advantage of being able to prepare artificial membranes with excellent separation performance, good thermal and chemical resistance and adaptability to the harsh wastewater environments [14].

\subsection{Blending PSF with Nanoparticles}

Blending involves firstly dissolving or dispersing the metal nanoparticles in a suitable solvent, which in the case of polysulfone is either $N, N^{\prime}$-dimethylacetamide (DMAc) or $N$-methyl-2-pyrrolidone (NMP). This solution is then sonicated for $72 \mathrm{hr}$ at approximately $60^{\circ} \mathrm{C}$ to obtain a uniform and homogeneous casting suspension. The polymer solution was then added to the metal nanoparticle solution and the mixture was then further sonicated for 1 week until a homogeneous solution was formed. Membranes were then cast onto a glass plate by phase inversion method $[15,16]$.

\subsection{Phase-Inversion}

Phase inversion is a process whereby a polymer is transformed in a controlled manner from a liquid to a solid state. The process of solidification is often initiated by the transition from one liquid state into two liquids (liquid-liquid demixing). At a certain stage during demixing, one of the liquid phases (the high polymer concentration phase) will solidify so that a solid matrix is formed. By controlling the initial stage of phase inversion the membrane morphology can be controlled i.e. porous as well as non-porous membranes can be prepared. The concept of phase inversion involves a range of different techniques such as solvent evaporation, thermal precipitation and immersion precipitation [17].

Most commercially available membranes are prepared using immersion precipitation. A solution of polymer and solvent was cast on a suitable support and immersed in a coagulation bath containing a nonsolvent. Precipitation occurred because of the exchange of solvent and nonsolvent and eventually the polymer was observed to precipitate. Water was most often used as nonsolvent, but organic solvents such as methanol could be used as well.The membrane structure ultimately obtained, resulted from a combination of mass transfer and phase separation [18-20].

Other preparation parameters that were considered, included evaporation time, polymer concentration, humidity, temperature and composition of casting solution. These parameters mainly determined the ultimate membrane performance.

\subsection{Metal Nanocomposite Membranes}

In recent years, various metal nanoparticles have been used in wastewater treatment membrane technology with various degrees of success. Previous studies have investigated the effectiveness of $\mathrm{TiO}_{2}, \mathrm{Ag}, \mathrm{Al}_{2} \mathrm{O}_{3}$ and most recently $\mathrm{ZrO}_{2}$ nanoparticles as membrane filler for the treatment of wastewater [21].

Metal nanocomposite membranes can remediate two types of fouling: membrane fouling due to organic matter and biofouling. Titania nanoparticles have mostly been used to mitigate the former. $\mathrm{Li}$ et al. showed that water flux through a polyethersulfone- $\mathrm{TiO}_{2}$ membrane was significantly enhanced, but that the flux effect was concentration dependent. This is due to nanoparticle agglomeration [22]. Due to their high diffusivity, nanoparticles exist as individual particles for only a short time and agglomerate rapidly, forming clusters that have an adverse effect on flux measurements. Other studies have however contradicted this finding and it must therefore be noted that different findings may arise from differences in procedures and materials [13].

Biofouling is counteracted by using the bactericidal properties of nanoparticles, of which silver is the most commonly used bactericide for fouling reduction. Silver impregnated membranes were proven to be effective against two strains of bacteria, E. coli K12 and P. mendocina KR1 thatwere both found in wastewater [23]. These membranes not only had antimicrobial properties, but they also prevented bacterial attachment to the membrane surface and thus reduced biofilm formation. Additionally, silver nanocomposite PSF membranes showed a significant improvement in virus removal from wastewater.

The most recent metal nanoparticle composite membranes that have been investigated for wastewater filtration are $\mathrm{Al}_{2} \mathrm{O}_{3} /$ polyethersulfone (PES) and $\mathrm{ZrO}_{2} / \mathrm{PES}$ 
membranes [24]. Maximous identified polymer concentration as the most important parameter for tailoring membrane properties. He found that with an increase in polymer concentration from $10 \%-18 \%$, the deionised water permeation decreased from $1227.4 \mathrm{~L} / \mathrm{m}^{2}$ bar-h to $866.5 \mathrm{~L} / \mathrm{m}^{2}$ bar-h suggesting that increased polymer concentration forms a thicker and denser skin layer. The steady state fouling rate of $\mathrm{Al}_{2} \mathrm{O}_{3}$ /polyethersulfone $(1.25$ $\mathrm{E}^{-11} \mathrm{~L} / \mathrm{m}^{2}$ bar-h) membranes was also found to be significantly lower than the unmodified PES membrane $(0.005$ $\mathrm{L} / \mathrm{m}^{2}$ bar-h). This is ascribed to the reduced hydrophobic adsorption between sludge particle and the $\mathrm{Al}_{2} \mathrm{O}_{3} /$ polyethersulfone (PES) membrane.

Maximous et al. extended this research to zirconia $\left(\mathrm{ZrO}_{2}\right)$, as zirconia membranes are known to be chemically more stable than titania and alumina membranes and therefore are more suitable for liquid phase applications under harsh conditions [24]. The addition of $\mathrm{ZrO}_{2}$ nanoparticles to the PES casting solution enhanced the membrane strength, but slightly affected the membrane thickness. The zirconia entrapped membrane also showed lower flux decline, improved total and cake resistance and fouling resistance compared to the unmodified membrane. The steady state fouling rate decreased from 0.005 to $1.04 \mathrm{E}^{-05} \mathrm{~L} / \mathrm{m}^{2}$ bar-h.

Chen et al. prepared embedded nano-iron polysulfone membranes for dehydration of ethanol/water mixtures by pervaporation [25]. It was found that the embedded nanoparticle slightly increased the flux and also increased the membrane separation factor. The nano-iron composite membrane showed improved hydrophylicity in terms of the permeation and sorption behaviour of embedded membranes, in that the nano iron affected the ordering or packing of the polymer chains and the particle oxide.

\section{Methods of Characterization}

Scanning electron microscopy (SEM) and Transmission Electron Microscopy (TEM) emerged from literature as the key tools used to indicate pore size, membrane thickness and surface morphology. Typically, membrane films were freeze-fractured in liquid nitrogen to obtain a tidy cross-section. The cross-section was used to determine the membrane thickness whereas the membrane surface was evaluated in terms of pore size.

To evaluate the hydrophilic properties of the membrane, contact angle measurements were used. A decrease in contact angle of the surface with water was used as an indication of improvement in the hydrophilic property of the membrane and vice versa. The liquid-membrane contact angle could range from $0^{\circ}-90^{\circ}$ and was primarily the function of membrane hydrophilicity. For an ideally hydrophilic membrane the contact angle should be 0 degrees, although this value is purely theoretical [17].

FTIR studies were performed on unmodified and modified membranes to determine the membrane structure and thus confirm the incorporation of metal nanoparticles. Physical tests on membrane structure included porosity analysis, permeability and rejection tests. In most cases membrane pores are not cylindrical holes cut perpendicularly through the membrane. Pores of a variety of shapes and sizes were found to be present on a single membrane. This internal network of different pore sizes was described as membrane porosity. Several methods were used to determine morphology of the pores, including microscopic measurements such as scanning electron microscopy, transmission electron microscopy and atomic force microscopy. The permeability of a membrane was defined as the ease of molecules to pass through it. Permeability was related to the electric charge of the molecule and to a lesser extent the molar mass of the molecule. Electrically neutral and small molecules were found to pass through the membrane easier than charged, large ones. The molecules that were unable to pass through the membrane were rejected [17]. Membrane fouling was assessed by evaluating changes in trans-membrane pressure (TMP). TMP was defined as the net driving pressure on the membrane. A clean membrane would have a relatively low TMP, whereas a fouled membrane will have a higher TMP.

A summary of these parameters for metal nanocomposite polysulfone membrane systems developed during the last decade as reported in literatureare given in Table $\mathbf{1 .}$

The grey areas in the table indicate that the relevant information was not reported in literature. From the table it is evident that there is a need for a lot more research to

Table 1. Summary of PSF-nanocompositescharacterization.

\begin{tabular}{|c|c|c|c|c|c|}
\hline Nanocomposite & Contact Angle $\left({ }^{\circ}\right)$ & $\%$ Rejection & $\begin{array}{l}\text { Pure Water Flux } \\
\qquad\left(1 / \mathrm{m}^{2} \cdot \mathrm{h}\right)\end{array}$ & $\begin{array}{l}\text { Steady State Fouling } \\
\text { rate }\left(\mathrm{L} / \mathrm{m}^{2} \text { bar-h }\right)\end{array}$ & $\begin{array}{c}\text { Filtration Resistance } \\
\mathrm{R}_{\mathrm{c}} / \mathrm{R}_{\mathrm{t}}(\%)\end{array}$ \\
\hline PSF-TiO ${ }_{2}$ & 41.4 & 90 & 230 & & 92.1 \\
\hline PES- $\mathrm{Al}_{2} \mathrm{O}_{3}$ & & & 600 & $1.25 \mathrm{E}^{-11}$ & 18 \\
\hline PSF-Ag & 68.6 & 70.9 & & & \\
\hline PES-ZrO & & & 500 & $1.04 \mathrm{E}^{-05}$ & \\
\hline PSF-Nanosilica & 41.7 & & 250 & & \\
\hline
\end{tabular}


be done before conclusions may be reached in terms of the most effective metal nanocomposite polysulfone membrane for treatment of wastewater. The most recently studied metal nanocomposites, PES- $\mathrm{ZrO}_{2}$ and PES- $\mathrm{Al}_{2} \mathrm{O}_{3}$, show good promise though as the initial flux of both membranes was approximately twice as high as the other reported metal nanocomposites. It must be noted that these studies were done with varying concentrations of the metal oxides and it was shown that with an increase of metal oxide, the membrane performance improved. In terms of membrane fouling mitigation the $0.05 \mathrm{ZrO}_{2} / \mathrm{PES}$ ratio $(w / w)$ was deemed optimum [24]. The surface hydrophilicity measured as membrane contact angle was however not reported in literature. The steady state fouling rate of the PES- $\mathrm{Al}_{2} \mathrm{O}_{3}$ membrane was found to be much slower than the PES- $\mathrm{ZrO}_{2}$, which could indicate a very hydrophilic membrane surface caused by nanoparticle entrapment. The $0.05 \mathrm{Al}_{2} \mathrm{O}_{3} / \mathrm{PES}$ ratio was also deemed to be optimum in terms of membrane fouling [14].

Metal oxides particles was found to have a higher affinity for water than the neat polymeric membrane, therefore hydrophobic adsorption between sludge particles and the nanoparticle entrapped membrane was reduced. Although the $\mathrm{PSF}_{-} \mathrm{TiO}_{2}$ membrane showed increased hydrophilicity in terms of contact angle measurement, it could be compared to the abovementioned nanocomposites in terms of the membrane flux. Bae and Tak found that the $\mathrm{TiO}_{2}$ nanoparticles not only adsorbed onto the membrane surface, but also into the membrane pores causing reduced membrane permeability and increased filtration resistance [26]. Nanoparticle concentration was therefore a crucial factor in metal nanocomposite synthe- sis as nanoparticles tend to form aggregates on the membrane surface that could lead to performance deterioration [27].

\subsection{Scanning Electron Microscopy}

Typical SEM results for the metal nanocomposite membranes indicated that membranes were highly porous and asymmetric with sponge-like structures. Cross-sectional morphology showed tear-shaped elongated macrovoids that extended from the compact skin layer towards the permeate side. The lower porosity skin layer was found to dominate the transport resistance of the composite membrane.

The morphologies of the membrane surface after metal nanoparticle addition showed an increase in the number of pores in the skin layer. The thickness of the skin layer increased with increased nanoparticle filler concentration; in contrast the finger-like macrovoids were suppressed or disappeared at high filler concentration.

\section{PES- $\mathrm{Al}_{2} \mathrm{O}_{3}$ Membrane}

Maximous et al. [14] investigated the distribution of $\mathrm{Al}_{2} \mathrm{O}_{3}$ inside the membrane matrix.

The asymmetry and porosity for the unmodified PES membrane are clearly evident (Figure 1). On the surface there is a denser skin layer, followed by finger-like macrovoids.

In this particular study, varying concentrations of $\mathrm{Al}_{2} \mathrm{O}_{3}$ nanoparticles were incorporated into the PES membrane in order to determine the nanoparticles distribution pattern within the membrane. The optimal distribution pattern was found with $0.05 \mathrm{Al}_{2} \mathrm{O}_{3} / \mathrm{PES}$ (Figure 2).

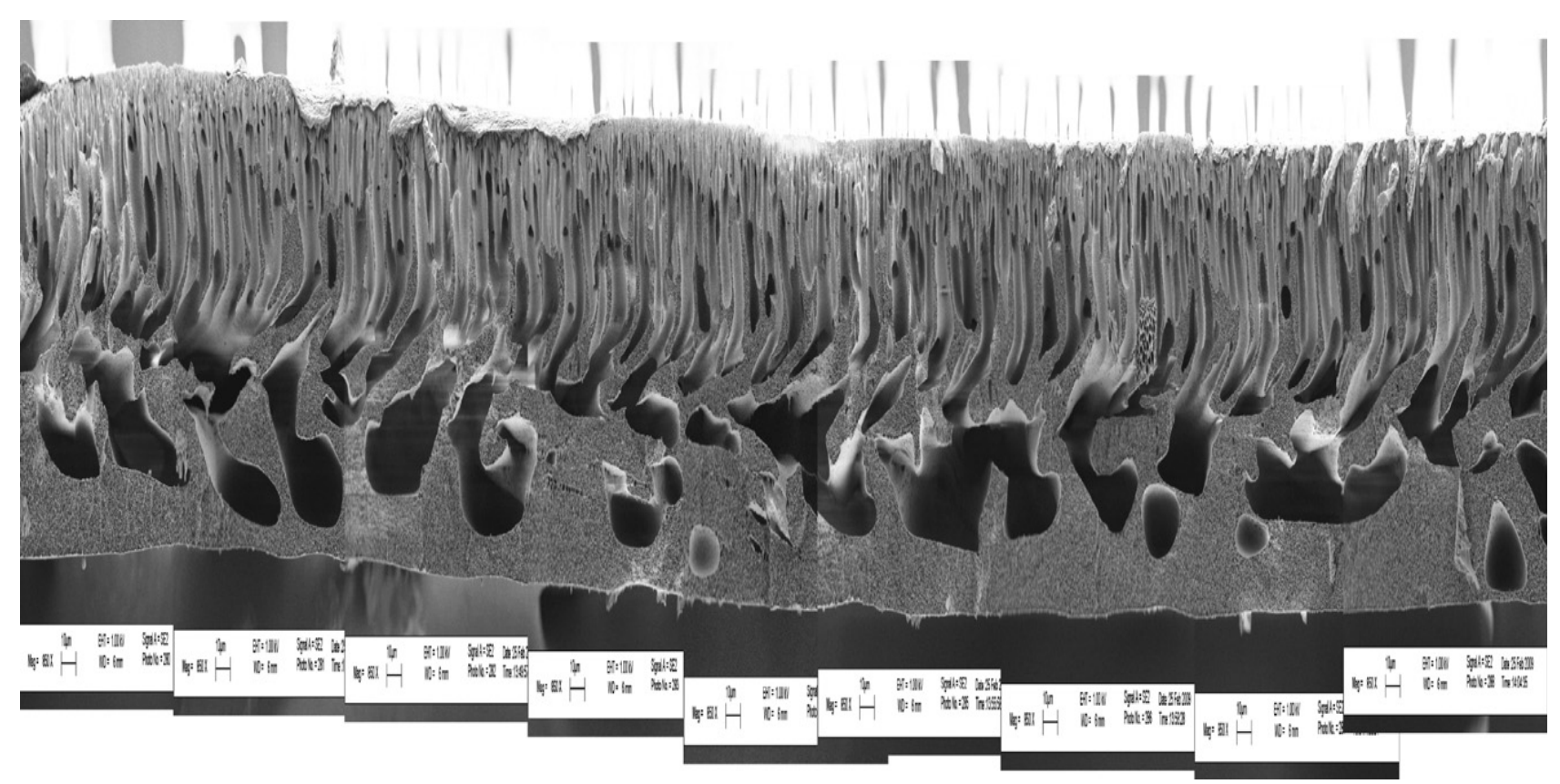

Figure 1. SEM of unmodified PES membrane. 

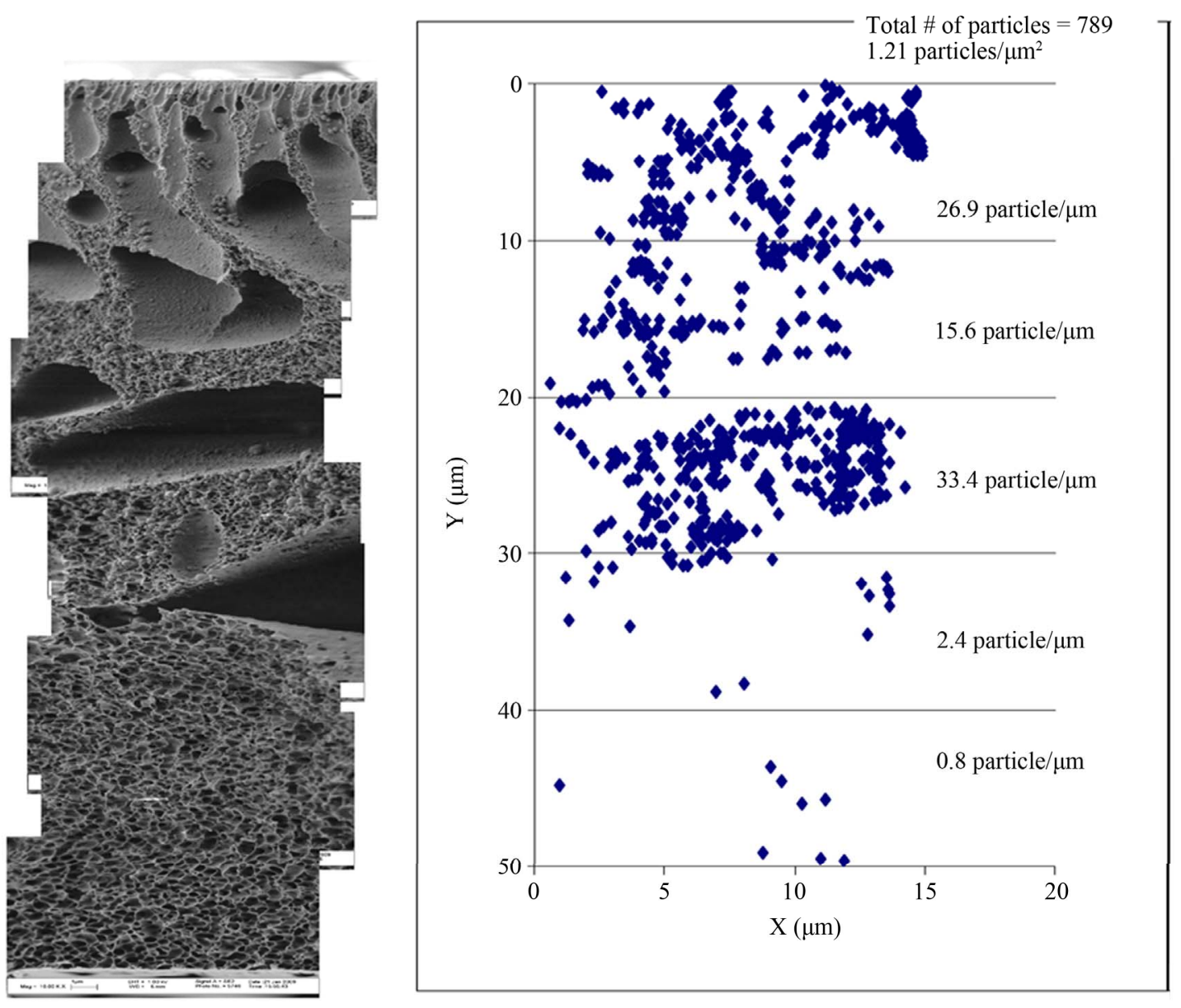

Figure 2. The $\mathrm{Al}_{2} \mathrm{O}_{3}$ distribution pattern in $0.05 \mathrm{Al}_{2} \mathrm{O}_{3} / \mathrm{PES}$.

It is clear that $42 \%$ of the $\mathrm{Al}_{2} \mathrm{O}_{3}$ nanoparticles were located at $20-30 \mu \mathrm{m}$ of membrane thickness. This was significantly higher than for $0.03 \mathrm{Al}_{2} \mathrm{O}_{3} / \mathrm{PES}$ where only about $25 \%$ of the nanoparticles were distributed in each $10 \mu \mathrm{m}$ of membrane thickness. Despite these differences, no relation between the $\mathrm{Al}_{2} \mathrm{O}_{3}$ particles distribution pattern inside the membrane matrix and the membrane performance could be concluded. However increased porosity and lower flux decline was achieved with $\mathrm{Al}_{2} \mathrm{O}_{3}$ nanoparticles incorporation.

\section{PES-ZrO}

All prepared membranes were observed to be highly porous and asymmetric with sponge-like structures (Figure 3). Increased particle density of $\mathrm{ZrO}_{2}$ in the 0.07 and 0.1 $\mathrm{ZrO}_{2} / \mathrm{PES}$ were clearly evident [24].

The particle density showed an increase with higher concentrations of $\mathrm{ZrO}_{2}$ nanoparticles, highlighting the potential for pore clogging as can be seen in Figure 3(f). This observation was supported by the increase in particle size to $400 \mathrm{~nm}$ in $0.1 \mathrm{ZrO}_{2} / \mathrm{PES}$ membranes (Figure 3(f)), compared to $200 \mathrm{~nm}$ for the other membranes. This could be due to particles agglomeration at high concentrations.

\section{PSF-TiO $_{2}$}

The SEM images in Figure $\mathbf{4}$ are cross-section morphologies of membranes and illustrate how the macrovoids grew at low filler concentration and then were suppressed or disappeared at higher filler concentration $(\geq 3$ $\mathrm{wt} \%$ ). It also indicated that the thickness of skinlayer increased with the increase of $\mathrm{TiO}_{2}$-filler concentration [13].

Figure 5 shows SEM images of $\mathrm{PSF}-\mathrm{TiO}_{2}$ membranesas obtained by Bae and Tak. The membrane surface shown in Figures 5(c) and (d) showed the $\mathrm{TiO}_{2}$ nanoparticles uniformly distributed on the membrane surface and pores, however some particles formed aggregates [26].

\section{PSF-Ag}

Zodrow et al. 2009 [16] found that the addition of Ag nanoparticles did not visibly alter the membrane structure. Taurozzi et al. 2008 [28] concurred with this finding when concluding that the effects of Ag nanoparticle filler incorporation were more pronounced for less porous membranes. Figure 6 shows very similar morphologies in the cross-section SEM for the PSF and the PSF-Ag membrane. A dense skin layer was observed at the surface, followed by very large macrovoids which indicated a very porous membrane structure. 


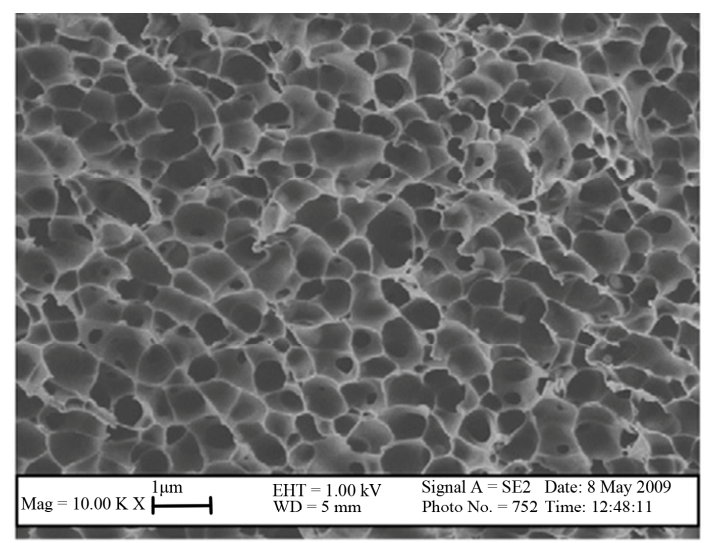

(a) neat PES

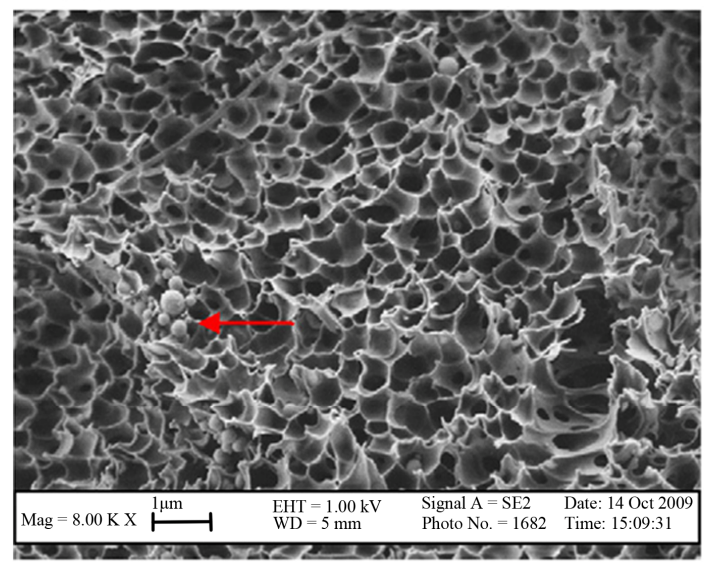

(c) $0.03 \mathrm{ZrO}_{2} / \mathrm{PES}$

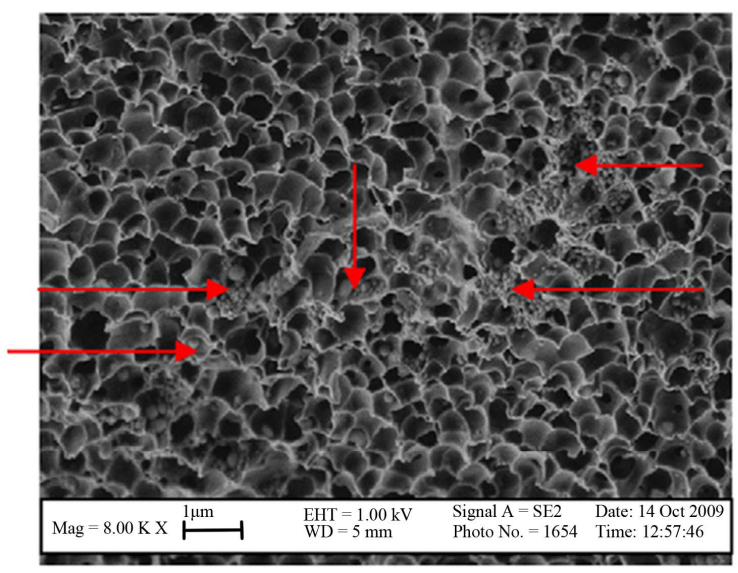

(e) $0.07 \mathrm{ZrO}_{2} / \mathrm{PES}$

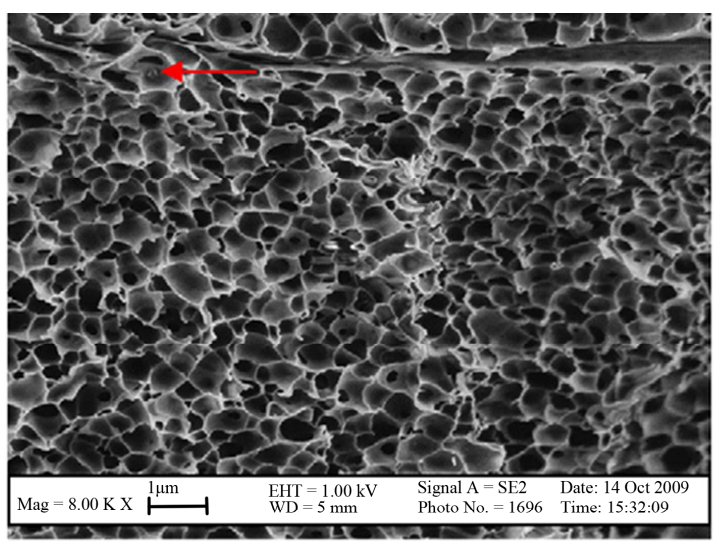

(b) $0.01 \mathrm{ZrO}_{2} / \mathrm{PES}$

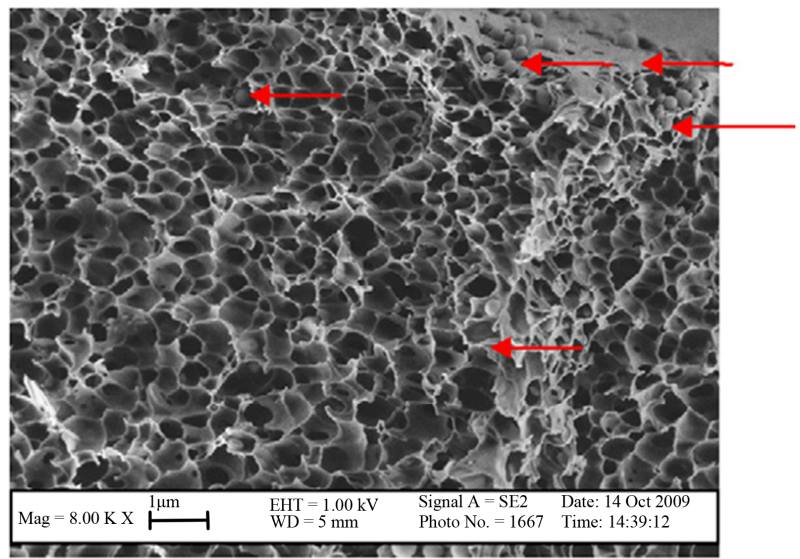

(d) $0.05 \mathrm{ZrO}_{2} / \mathrm{PES}$

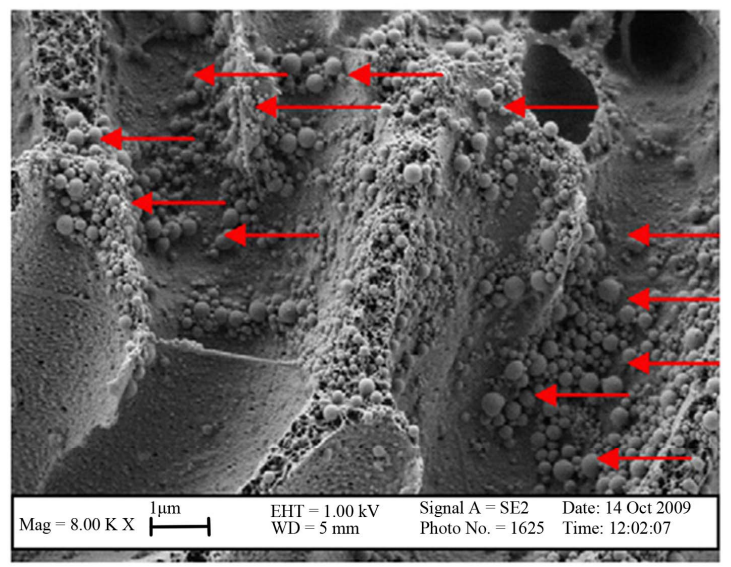

(f) $0.1 \mathrm{ZrO}_{2} / \mathrm{PES}$

Figure 3. SEM images for the neat and $\mathrm{ZrO}_{2} / \mathrm{PES}$ membranes synthesized with different concentrations of $\mathrm{ZrO}_{2}$.

\subsection{Summary of SEM Results}

Yanan et al. concluded that a higher $\mathrm{TiO}_{2}$ filler concentration induced an apparent aggregate phenomenon and produced a considerable number of large surface pores mostly formed in the vicinity of $\mathrm{TiO}_{2}$ aggregates [13]. These findings indicated that interfacial stresses existed between polymer and filler, which increased and were finally relaxed by forming interfacial pores due to shrinkage of the organic phase during the demixing process.

In all the studies discussed in this review, it was proven that the addition of metal nanoparticles increased the membrane porosity. However, the optimum concentration of nanoparticles filler was crucial in this process in order to avoid nanoparticle clogging of membrane pores. The SEM results for all the nanocomposites discussed 


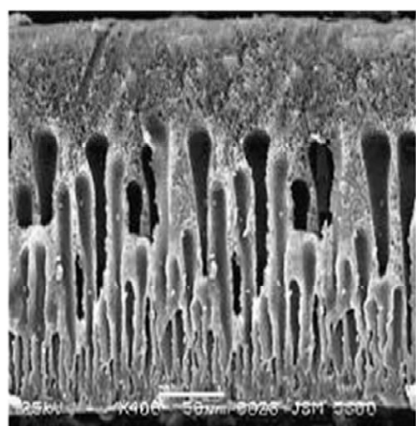

(a)

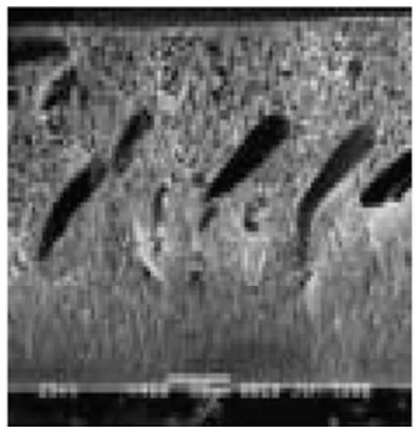

(d)

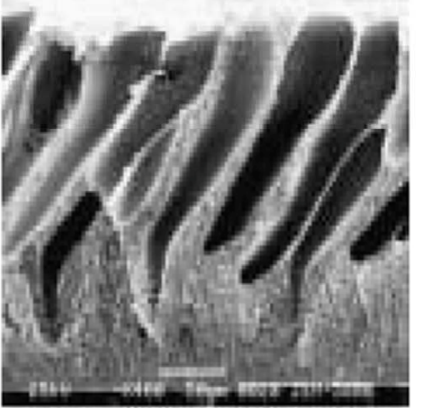

(b)

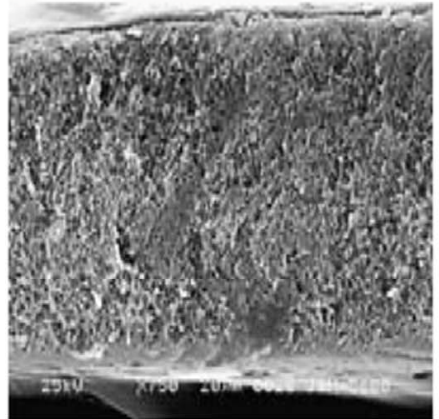

(e)

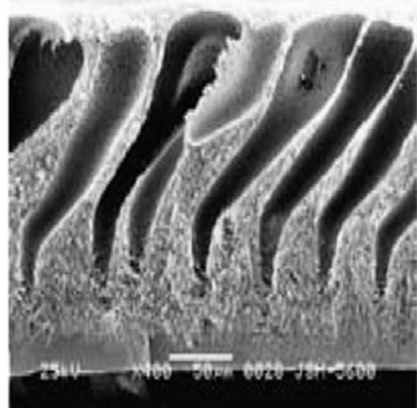

(c)

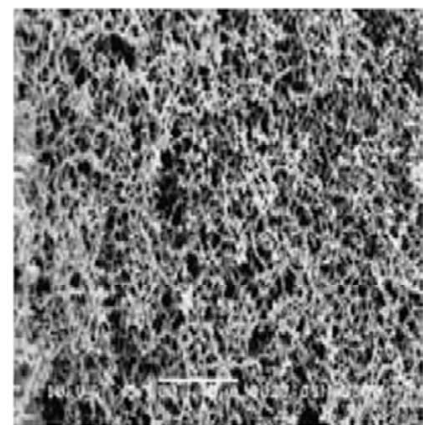

(f)

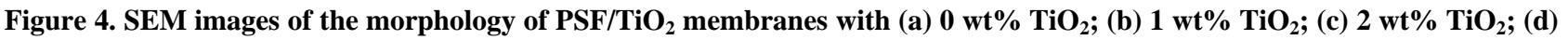
$3 \mathrm{wt} \% \mathrm{TiO}_{2}$; (e) $5 \mathrm{wt} \% \mathrm{TiO}_{2}$; and (f) E's local magnifying figure.
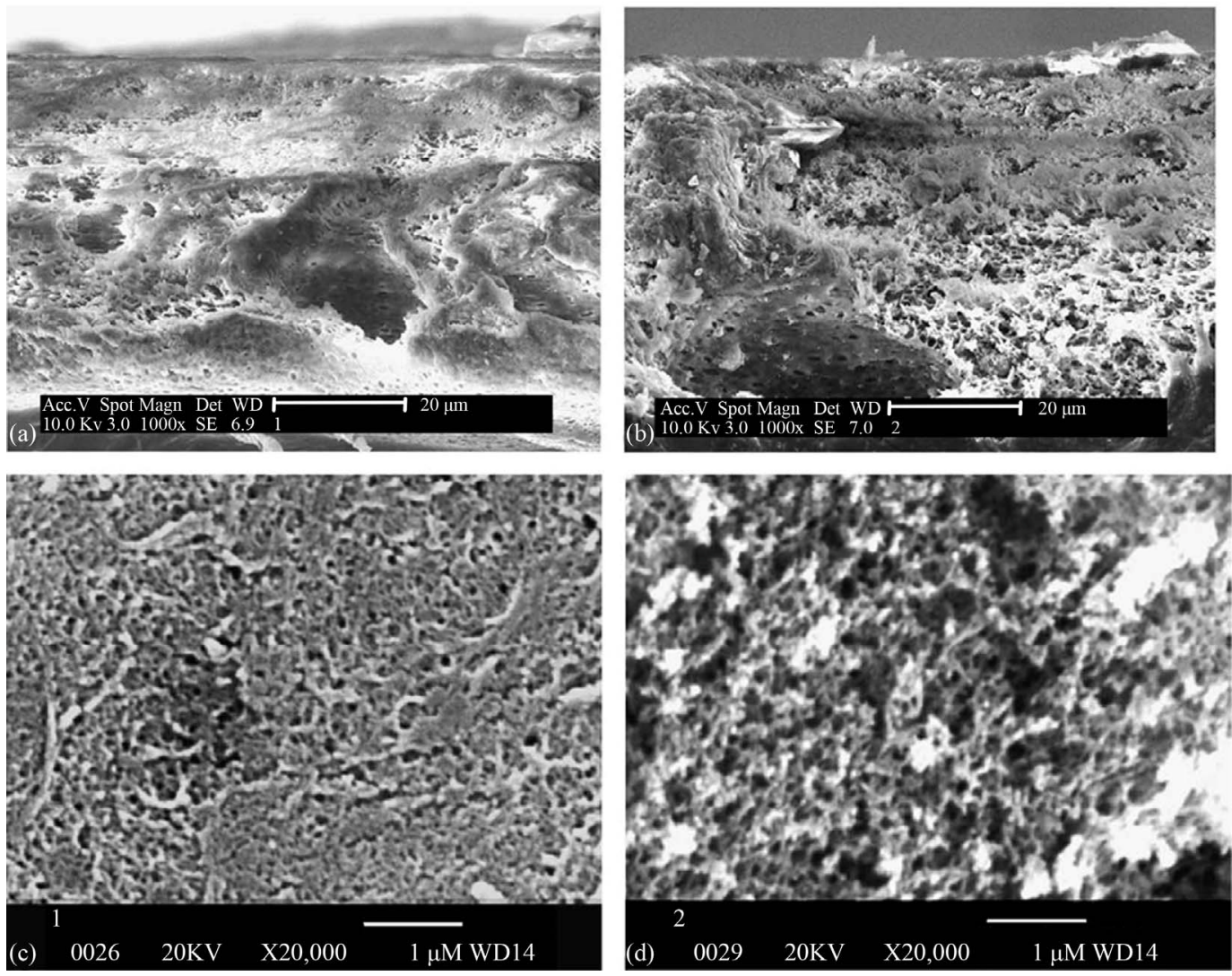

Figure 5. SEM images of neat and $\mathrm{TiO}_{2}$ entrapped PSf membrane $\left(\mathrm{TiO}_{2} / \mathrm{PSf}=\mathbf{0 . 3}\right)$ : (a) Cross-section of PSf; (b) Cross-section of $\mathrm{TiO}_{2}$-PSf; (c) Surface of PSf; and (d) Surface of $\mathrm{TiO}_{2}-\mathrm{PSf}$. 

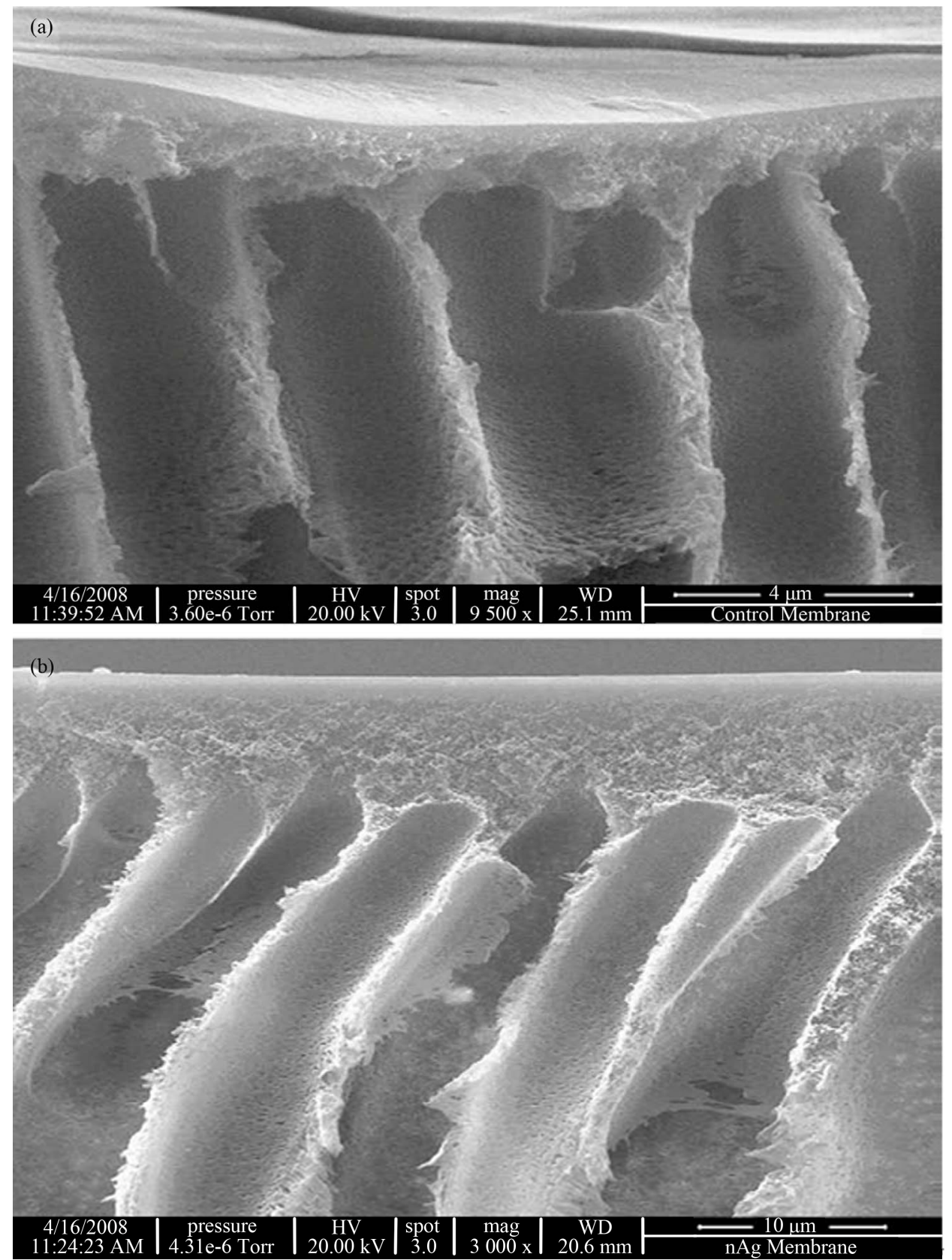

Figure 6. SEM cross-section of (a) PSF and (b) PSF-Ag membranes.

here were very similar and therefore it was difficult to conclude from these results alone which metal nanocomposite was the most effective.

\section{Hydrophobicity and Hydrophilicity}

Hydrophilicity may be characterized in general terms as the affinity of the membrane material for water or ability of the membrane to become wetted with water. It has generally been agreed that the increase of membrane hydrophilicity could reduce its fouling [29]. Hydrophobic interaction between solutes or microbial cells and mem- brane material was regarded as one of the predominant fouling mechanisms. Therefore membrane fouling was expected to be more severe for hydrophobic than hydrophilic membranes [30,31].

There has been much research into the hydrophilization of ultrafiltration membrane materials, including blending of a hydrophilic polymer or metal nanoparticles, with the membrane-forming polymer to obtain hydrophilic membranes. Hydrophilic polymer additives included-polyvinylpyrrolidone (PVP) and polyethylene glycol (PEG) [32-34]. Despite its importance, only few studies focused on the influence of different polymeric membrane materi- 
als on membrane fouling in MBRs. It has been reported that hydrophilic cellulosic membrane, experience less fouling than hydrophobic polysulfone membranes [35]. However, other researchers have reported that the hydrophobic membranes have a relatively low fouling tendency with less adsorption onto the surface compared to hydrophilic counterparts [36].

Choo and Lee investigated the novel approach to better understand fouling in terms of surface energy charges involved. They tested three different types of membrane materials i.e. cellulosics, polysulfone and fluoropolymers and found the most hydrophobic fluoropolymer to show the lowest fouling tendency [37]. A commonly known fluoropolymer is Teflon. It was shown that further changes in membrane hydrophobicity occurred with membrane modifications such as pore size and morphology. This fact makes the correlation between membrane hydrophobicity and fouling more difficult to assess [38]. In fact, Maximous et al. concluded in 2009 that in the case of sludge filtration for hydrophilic and hydrophobic membranes, hydrophilicity does not seem advantageous from the fouling propensity. Hydrophilic membranes do however have higher cake resistance reversibility than hydrophobic membranes.

When comparing polymer membranes with hydrophilic properties, cellulose membranes showed remarkable hydrophilic properties due to three active hydroxyls in each repeating unit of cellulose molecule (Figure 7) [16].

The strong hydrogen bonds that occur between cellulose chains prevents dissolution in ordinary solvents and it can withstand very high temperatures. Cellulose acetate and regenerated cellulose membranes have been widely applied in technologies such as ultrafiltration, microfiltration and dialysis. However, cellulose was degraded during the regeneration process and this caused irreversible damage to its ability of enduring strong acid, alkali and organic solvents, as well as serious environmental problems.

Because of its robustness and its ability to withstand strong acids and alkalis, polysulfone and polyethersulfone still remain a more practical choice for membrane filtration than the more hydrophilic cellulosics.

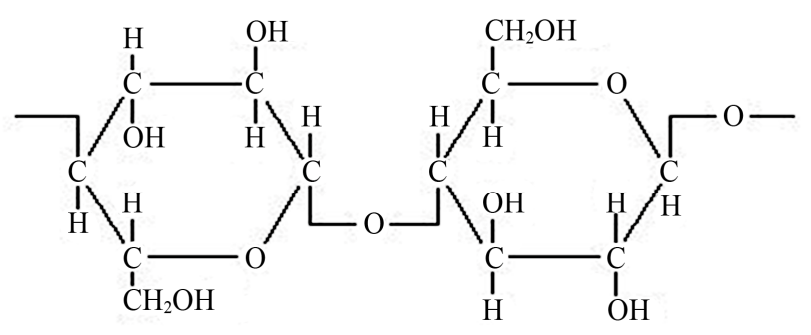

Cellulose

Figure 7. Structure of cellulose.
In order to develop membrane systems with reduced fouling capability, the focus of future research should consider the incorporation of a wider range of metal nanoparticles, over and above the ones already identified from literature. Preferably the selection of metal nanoparticles should follow a periodic trend, in order to establish trends with respect to chemical properties of the metal nanoparticle incorporated. Careful consideration should also be given to the concentration levels at which metal nanoparticles are introduced, in order to avoid the phenomenon of pore clogging due to agglomeration of metal nanoparticles at higher concentration.

The main categories of suitable membrane matrices identified in the review were cellulose and polysulfone membranes in terms of processability cost and most importantly fouling resistance. In the absence of novel matrices with superior characteristics in all respects, immediate future research should look at these matrices appropriately modified, as a new generation of membrane materials for metal nanoparticle incorporation. However, the search for completely novel membrane materials should be regarded as a priority research area too, since there is still great disparity among authors in terms of the ultimate superiority of either cellulose or polysulfone and their derivatives studied to date.

\section{Conclusions}

To date $\mathrm{TiO}_{2}$-PSF and Ag-PSF nanocomposite membranes are the most researched when it comes to the area of water- and wastewater treatment.

Ag-PSF membranes have been proven to have antimicrobial properties and prevent bacterial attachment onto the membrane surface, thereby reducing biofilm formation.

Membrane characteristics were changed by the addition of $\mathrm{TiO}_{2}, \mathrm{Ag}, \mathrm{Al}_{2} \mathrm{O}_{3}$ and $\mathrm{ZrO}_{2}$ nanoparticles and nanosilica to the casting solutions. Tensile strength and hydrophilic property was enhanced, but other physical characteristics such as membrane thickness was negatively affected. The thickness of skinlayer increased with increase of filler concentration.

SEM micrographs for all metal nanocomposite membrane show an asymmetric membrane that consists of a compact layer and a porous layer. The addition of metal nanoparticle fillers resulted in the increase of pore numbers in the porous skin layer compared with the PSF membrane. Hydrophilicity was increased due to the antifouling ability of the membrane, which in turn also enhanced the membrane flux. Contact angle was reduced by the addition of metal nanoparticle fillers for selected nanocomposites from literature, where data was available. The cost associated with membrane production and maintenance of membrane operating systems could thus far not be significantly reduced. 


\section{REFERENCES}

[1] N. Savage and M. S. Diallo, "Nanomaterials and Water Purification: Opportunities and Challenges," Journal of Nanoparticle Research, Vol. 7, No. 4-5, 2005, pp. 331342. doi:10.1007/s11051-005-7523-5

[2] E. M. V. Hoek and A. K. Ghosh, "Nanotechnology-Based Membranes for Water Purification," In: N. Savage, M. Diallo, J. Duncan, A. Street and R. Sustich, Eds., Nanotechnology Applications for Clean Water, William Andrew Publishing, Boston, 2009, pp. 47-58.

[3] P. Le-Clech, V. Che and T. A. G. Fane, "Fouling in Membrane Bioreactors Used in Wastewater Treatment," Journal of Membrane Science, Vol. 284, No. 1-2, 2006, pp. 17-53. doi:10.1016/j.memsci.2006.08.019

[4] P. Xu, C. Bellona and J. E. Drewes, "Fouling of Nanofiltration and Reverse Osmosis Membranes during Municipal Wastewater Reclamation: Membrane Autopsy Results from Pilot-Scale Investigations," Journal of Membrane Science, Vol. 353, No. 1-2, 2010, pp. 111-121. doi:10.1016/j.memsci.2010.02.037

[5] J. Zhang, H. C. Chua, J. Zhou and A. G. Fane, "Factors Affecting the Membrane Performance in Submerged Membrane Bioreactors," Journal of Membrane Science, Vol. 284, No. 1-2, 2006, pp. 54-66. doi:10.1016/j.memsci.2006.06.022

[6] H.-H. Ngo and W. Guo, "Membrane Fouling Control and Enhanced Phosphorus Removal in an Aerated Submerged Membrane Bioreactor Using Modified Green Bioflocculant," Bioresource Technology, Vol. 100, No. 18, 2009, pp. 4289-4291. doi:10.1016/j.biortech.2009.03.057

[7] Y. Shen, W. Zhao, K. Xiao and X. Huang, "A Systematic Insight into Fouling Propensity of Soluble Microbial Products in Membrane Bioreactors Based on Hydrophobic Interaction and Size Exclusion," Journal of Membrane Science, Vol. 346, No. 1, 2010, pp. 187-193. doi:10.1016/j.memsci.2009.09.040

[8] H. K. Shon, S. Vigneswaran, I. S. Kim, J. Cho and H. H. Ngo, "Fouling of Ultrafiltration Membrane by Effluent Organic Matter: A Detailed Characterization Using Different Organic Fractions in Wastewater," Journal of Membrane Science, Vol. 278, No. 1-2, 2006, pp. 232-238. doi:10.1016/j.memsci.2005.11.006

[9] J. Lee, W. Ahn and C. Lee, "Comparison of the Filtration Characteristics between Attached and Suspended Growth Microorganisms in Submerged Membrane Bioreactor," Water Research, Vol. 35, No. 10, 2001, pp. 2435-2445. doi:10.1016/S0043-1354(00)00524-8

[10] H. Hua, N. Li, L. Wu, H. Zhong, G. Wu, Z. Yuan, X. Lin and L. Tang, "Anti-Fouling Ultrafiltration Membrane Prepared from Polysulfone-Graft-Methyl Acrylate Copolymers by UV-Induced Grafting Method," Journal of Environmental Sciences, Vol. 20, No. 5, 2008, pp. 565-570. doi:10.1016/S1001-0742(08)62095-1

[11] H. Ivnitsky, D. Minz, L. Kautsky, A. Preis, A. Ostfeld, R. Semiat and C. G. Dosoretz, "Biofouling Formation and Modeling in Nanofiltration Membranes Applied to Wastewater Treatment," Journal of Membrane Science, Vol. 360, No. 1-2, 2010, pp. 165-173. doi:10.1016/j.memsci.2010.05.007
[12] M. Herzberg, D. Berry and L. Raskin, "Impact of Microfiltration Treatment of Secondary Wastewater Effluent on Biofouling of Reverse Osmosis Membranes," Water Research, Vol. 44, No. 1, 2010, pp. 167-176. doi:10.1016/j.watres.2009.09.022

[13] Y. Yanan, Z. Huixuan, W. Peng, Z. Qingzhu and L. Jun, "The Influence of Nano-Sized $\mathrm{TiO}_{2}$ Fillers on the Morphologies and Properties of PSF UF Membrane," Journal of Membrane Science, Vol. 288, No. 1-2, 2007, pp. 231-238. doi:10.1016/j.memsci.2006.11.019

[14] N. Maximous, G. Nakhla, W. Wan and K. Wong, "Preparation, Characterization and Performance of $\mathrm{Al}_{2} \mathrm{O}_{3} / \mathrm{PES}$ Membrane for Wastewater Filtration," Journal of Membrane Science, Vol. 341, No. 1-2, 2009, pp. 67-75. doi:10.1016/j.memsci.2009.05.040

[15] Z. G. Wu, M. Munoz and O. Montero, "The Synthesis of Nickel Nanoparticles by Hydrazine Reduction," Advanced Powder Technology, Vol. 21, No. 2, 2009, pp. 165-168.

[16] F. Guo, H. Zheng, Z. Yang and Y. Qian, "Synthesis of Cobalt Nanoparticles in Ethanol Hydrazine Alkaline System (EHAS) at Room Temperature," Materials Letters, Vol. 56, No. 6, 2002, pp. 906-909. doi:10.1016/S0167-577X(02)00635-3

[17] J. Mulder, "Basic Principles of Membrane Technology," 2nd Edition, Kluwer Academic Publishers, Dordrecht, 1996, p. 584. doi:10.1007/978-94-009-1766-8

[18] A. Rahimpour, "UV Photo-Grafting of Hydrophilic Monomers onto the Surface of Nano-Porous PES Membranes for Improving Surface Properties," Desalination, Vol. 265, No. 1-3, 2011, pp. 93-101.

[19] A. Rahimpour, S. S. Madaeni, M. Jahanshahi, Y. Mansourpanah and N. Mortazavian, "Development of High Performance Nano-Porous Polyethersulfone Ultrafiltration Membranes with Hydrophilic Surface and Superior Antifouling Properties," Applied Surface Science, Vol. 255, No. 22, 2009, pp. 9166-9173. doi:10.1016/j.apsusc.2009.06.123

[20] H. Susanto, N. Stahra and M. Ulbricht, "High Performance Polyethersulfone Microfiltration Membranes Having High Flux and Stable Hydrophilic Property," Journal of Membrane Science, Vol. 342, No. 1-2, 2009, pp. 153-164. doi:10.1016/j.memsci.2009.06.035

[21] K. Zodrow, L. Brunet, S. Mahendra, D. Li, A. Zhang, Q. $\mathrm{Li}$ and P. J. J. Alvarez, "Polysulfone Ultrafiltration Membranes Impregnated with Silver Nanoparticles Show Improved Biofouling Resistance and Virus Removal," Water Research, Vol. 43, No. 3, 2009, pp. 715-723. doi:10.1016/j.watres.2008.11.014

[22] J. Kim and B. Van der Bruggen, "The Use of Nanoparticles in Polymeric and Ceramic Membrane Structures: Review of Manufacturing Procedures and Performance Improvement for Water Treatment," Environmental Pollution, Vol. 158, No. 7, 2010, pp. 2335-2349. doi:10.1016/j.envpol.2010.03.024

[23] H. Omidian, J. G. Rocca and K. Park, “Advances in Superporous Hydrogels," Journal of Controlled Release, Vol. 102, No. 1, 2005, pp. 3-12. doi:10.1016/i.jconrel.2004.09.028

[24] N. Maximous, G. Nakhla, W. Wan and K. Wong, "Perfor- 
mance of a Novel $\mathrm{ZrO}_{2} / \mathrm{PES}$ Membrane for Wastewater Filtration," Journal of Membrane Science, Vol. 352, No. 1-2, 2010, pp. 222-230.

[25] S. Chen, R. Liou, C. Lai, M. Hung, M. Tsai and S. Huang, "Embedded Nano-Iron Polysulfone Membrane for Dehydration of the Ethanol/Water Mixtures by Pervaporation," Desalination, Vol. 234, No. 1-3, 2008, pp. 221-231. doi:10.1016/i.desal.2007.09.089

[26] T. Bae and T. Tak, "Effect of $\mathrm{TiO}_{2}$ Nanoparticles on Fouling Mitigation of Ultrafiltration Membranes for Activated Sludge Filtration," Journal of Membrane Science, Vol. 249, No. 1-2, 2005, pp. 1-8. doi:10.1016/j.memsci.2004.09.008

[27] L. Y. Ng, A. W. Mohammad, C. P. Leo and N. Hilal, "Polymeric Membranes Incorporated with Metal/Metal Oxide Nanoparticles: A Comprehensive Review," Desalination, 2010, in Press. doi:10.1016/j.desal.2010.11.033

[28] J. S. Taurozzi, H. Arul, V. Z. Bosak, A. F. Burban, T. C. Voice, M. L. Bruening and V. V. Tarabara, "Effect of Filler Incorporation Route on the Properties of PolysulfoneSilver Nanocomposite Membranes of Different Porosities," Journal of Membrane Science, Vol. 325, No. 1, 2008, pp. 58-68. doi:10.1016/j.memsci.2008.07.010

[29] H. Li, Y. Cao, J. Qin, X. Jie, T. Wang, J. Liu and Q. Yuan, "Development and Characterization of Anti-Fouling Cellulose Hollow Fiber UF Membranes for Oil-Water Separation," Journal of Membrane Science, Vol. 279, No. 1-2, 2006, pp. 328-335. doi:10.1016/j.memsci.2005.12.025

[30] H.-Y. Yu, M.-X. Hu, Z.-K. Xu, J.-L. Wang and S.-Y. Wang, "Surface Modification of Polypropylene Microporous Membranes to Improve Their Antifouling Property in MBR: $\mathrm{NH}_{3}$ Plasma Treatment," Separation and Purification Technology, Vol. 45, No. 1, 2005, pp. 8-15. doi:10.1016/j.seppur.2005.01.012

[31] Q. Sun, Y. Su, X. Ma, Y. Wang and Z. Jiang, "Improved Antifouling Property of Zwitterionic Ultrafiltration Mem- brane Composed of Acrylonitile and Sulfobetaine Copolymer," Membrane Science, Vol. 285, No. 1-2, 2006, pp. 299-305. doi:10.1016/j.memsci.2006.08.035

[32] N. A. Hashim, F. Liu and K. Li, "A simplified Method for Preparation of Hydrophilic PVDF Membranes from an Amphiphilic Graft Copolymer," Journal of Membrane Science, Vol. 345, No. 1-2, 2009, pp. 134-141. doi:10.1016/j.memsci.2009.08.032

[33] H. Ju, B. D. McCloskey, A. C. Sagle, V. A. Kusuma and B. D. Freeman, "Preparation and Characterization of Crosslinked Ploy(Ethylene Glycol) Diacrylate Hydrogels as Fouling-Resistant Membrane Coating Materials," Journal of Environmental Sciences, Vol. 330, No. 1-2, 2009, pp. 180-188.

[34] A. C. Sagle, H. Ju, B. D. Freeman and M. M. Sharma, "PEG-Based Hydrogel Membrane Coatings," Polymer, Vol. 50, No. 3, 2009, pp. 756-766. doi:10.1016/j.polymer.2008.12.019

[35] J. A. Howell, V. Sanchez and R. W. Field, "Membranes in Bioprocessing: Theory and Application," Chapman \& Hall, Cambridge, 1993. doi:10.1007/978-94-011-2156-9

[36] T. Nomura, T. Fujii and M. Suzuki, "Application of the Ceramic Membrane with Hydrophobic Skin Layer to Separation of activated Sludge," Water Science and Technology, Vol. 35, No. 8, 1997, pp. 137-144. doi:10.1016/S0273-1223(97)88226-1

[37] K. H. Choo and C. H. Lee, "Understanding Membrane Fouling in Terms of Surface Free Energy Changes," Colloid Interface Science, Vol. 226, No. 2, 2000, pp. 367-370. doi:10.1006/jicis.2000.6845

[38] N. Maximous, G. Nakhla and W. Wan, "Comparative Assessment of Hydrophobic and Hydrophilic Membrane Fouling in Wastewater Applications," Journal of Membrane Science, Vol. 339, No. 1-2, 2009, pp. 93-99. doi:10.1016/j.memsci.2009.04.034 